\title{
Paraesophageal hernia: to fundoplicate or not?
}

\author{
Daniel Solomon, Eliahu Bekhor, Hanoch Kashtan
}

Department of General Surgery, Rabin Medical Center, Campus Beilinson, Affiliated with Sackler Faculty of Medicine, Tel Aviv University, Petach-Tikva, Israel

Contributions: (I) Conception and design: H Kashtan, D Solomon; (II) Administrative support: H Kashtan; (III) Provision of study materials or patients: D Solomon, E Bekhor; (IV) Collection and assembly of data: D Solomon, E Bekhor; (V) Data analysis and interpretation: H Kashtan, D Solomon; (VI) Manuscript writing: All authors; (VII) Final approval of manuscript: All authors.

Correspondence to: Prof. Hanoch Kashtan. Department of General Surgery, Rabin Medical Center, Campus Beilinson, Jabotinsky Str. 39, PetachTikva, 49100, Israel. Email: hkashtan@clalit.org.il.

\begin{abstract}
The need for an antireflux procedure during repair of a paraesophageal hernia $(\mathrm{PEH})$ has been the subject of a long-standing controversy. With most centers now performing routine fundoplication during $\mathrm{PEH}$ repair, high-quality data on whether crural repair alone or using a mesh may provide adequate antireflux effect is still scarce. We sought to answer to the question: "Is fundoplication routinely needed during $\mathrm{PEH}$ repair?”. Our endpoints were (I) rates of postoperative gastroesophageal reflux disease (GERD) (either symptomatic or objectively assessed), (II) rates of recurrence, and (III) rates of postoperative dysphagia. We searched the MEDLINE, Cochrane, PubMed, and Embase databases for papers published between 1995 and 2019, selecting comparative cohort studies and only including papers reporting the rationale for performing or not performing fundoplication. Overall, nine papers were included for review. While four of the included studies recommended selective or no fundoplication, most of these data come from earlier retrospective studies. Higher-quality data from recent prospective studies including two randomized controlled trials recommended routine fundoplication, mostly due to a significantly lower incidence of postoperative GERD. However, only a relatively short follow-up of 12 months was presented, which we recognize as an important limitation. Fundoplication did not seem to result in reduced recurrence rates when compared to primary repair alone.
\end{abstract}

Keywords: Paraesophageal hernia (PEH); fundoplication; reflux

Submitted Jan 11, 2020. Accepted for publication Mar 02, 2020.

doi: $10.21037 / \mathrm{atm} .2020 .03 .106$

View this article at: http://dx.doi.org/10.21037/atm.2020.03.106

\section{Introduction}

\section{An historical perspective of hiatal hernia and reflux disease}

Hiatal hernia has been reported in medical literature since the $16^{\text {th }}$ century (1), but only in 1853 Henry Ingersoll Bowditch, in his "Treatise on diaphragmatic hernia", systematically reviewed all previously described cases and developed a classification system (2). Bowditch included three cases in which the esophagus "descended through the diaphragm [...] but turned back towards the left to enter the abnormal aperture caused by the hernia and to join the stomach in the chest", describing a paraesophageal hernia (PEH) for the first time (2). Almost 80 years later, Ảke
Åkerlund (3) classified hiatal hernias recognizing sliding and $\mathrm{PEH}$, and identified heartburn as a common symptom. Today, hiatal hernia is defined as the herniation of a portion of the stomach through the diaphragmatic hiatus (4), and is further classified in type I (intrathoracic displacement of the gastroesophageal junction), type II (true PEH, intrathoracic herniation of the proximal stomach with gastroesophageal junction in normal position), type III (intrathoracic displacement of both stomach and gastroesophageal junction), and type IV (herniation of abdominal viscera other than stomach) (5). While $90-95 \%$ of patients are diagnosed type I hernias, a diagnosis of $\mathrm{PEH}$ is associated with a higher risk of life-threatening complications such 
as strangulation, hemorrhage, volvulus, and perforation, and surgical treatment is often recommended $(5,6)$. As Åkerlund pointed out more than a century ago, heartburn is a frequent complaint among patients suffering from hiatal hernia and symptoms associated with gastroesophageal reflux disease (GERD) have been reported in up to $83 \%$ of cases $(4,7-9)$.

\section{PEH and gastroesophageal reflux: common patbways}

A growing literature on the subject led to the recognition of different structures that contribute to an anatomic antireflux (AR) barrier, including the lower esophageal sphincter (LES), the crural diaphragm, the angle of His and the gastroesophageal flap valve (10). The process leading to the formation of hiatal hernia involves the disruption of this barrier through different pathways. Initially, the crural diaphragm and the angle of His were considered the main factors responsible for the correct functioning of the AR barrier. Considered the father of modern AR surgery, Philip Allison in 1951 focused on the crural sling as the key factor in preventing reflux, describing the role of its muscles as a pinchcock on the gastroesophageal junction (11). More recently, it has been demonstrated that the crural diaphragm alone is able to create a high-pressure zone at the abdominothoracic junction in patients who are lacking gastroesophageal junction following esophagogastrectomy (12). Besides the anatomic disruption of the crural diaphragm associated with hiatal hernias, pathologic alterations of the crural diaphragm have been described on a microanatomic level as well, as reported in the interesting work from Fei $e t a l$. In their study, laparoscopic biopsy of the muscular and connective components of the esophageal hiatus were obtained from 19 patients affected by hiatal hernia and GERD and from seven controls, and degenerative changes were found in crural muscles from all patients from the hiatal hernia group, whereas no alteration was found in the specimens from the control group (13). In addition to a defective crural diaphragm, patients with hiatal hernia present lower LES pressures than patients without hernias or volunteers (14). Fein et al. demonstrated that a hiatal hernia results in a shortening of the LES and in reduced resting pressure, both associated independently with abnormal esophageal acid exposure (15). Lastly, the anatomic separation between the intrinsic LES and the diaphragmatic crura can lead to a lack of functional synergy, and the resulting breakout of peristaltic clearing has been associated with prolonged acid exposure (16). Indeed, a recent study on 37 patients suffering from GERD, confirmed that hiatal hernia is a strong predictor of prolonged proximal esophageal acid exposure (17).

\section{Review question}

Ideally, reducing the hernia sac relocates the LES in its natural position, and primary or mesh-reinforced closure of the diaphragmatic defect restores the highpressure zone created by the crural muscles. The need for an antireflux procedure such as a fundoplication in this setting has been the subject of a long-standing controversy. With most centers now performing routine fundoplication during PEH repair, high-quality data on whether crural repair alone or using a mesh may provide adequate $A R$ effect is still scarce (18).

We sought to answer to the question: "Is fundoplication routinely needed during PEH repair?”.

\section{Materials and methods}

A PICO (participants, intervention, control, and outcome) model was constructed. We included prospective and retrospective cohort studies on adults $>18$ years old diagnosed with $\mathrm{PEH}$ (population) comparing patients who underwent fundoplication following PEH repair (intervention, AR group) to patients how underwent $\mathrm{PEH}$ repair alone, either primary or mesh-reinforced [control, no anti-reflux (NAR) group]. Primary outcomes of our review included (I) incidence of GERD, either reported subjectively in validated questionnaires or objectively as the results of endoscopic, radiologic, manometric, and $\mathrm{pH}$ metric measurements, and (II) recurrence rate detected at postoperative imaging. As a secondary outcome, we sought to investigate postoperative rates of dysphagia across the two cohorts.

We searched the PubMed, Embase, and Cochrane databases for papers published between 1995 and 2019 . Search strings adopted in each database are reported in Table 1. Gray literature was also included in our search. We selected comparative cohort studies, either prospective or retrospective. We included papers reporting the rationale for performing or not performing an anti-reflux procedure. Technical reports, case reports, narrative reviews, and papers including a pediatric population were excluded from review. We combined all abstracts in a single list, resulting in 2,200 studies. After duplication control, a total of 128 studies were evaluated according to the guidelines from Preferred Reporting Items for Systematic Reviews and Meta-Analyses 
Table 1 Search strings for PubMed, EMBASE, and Cochrane library

\begin{tabular}{|c|c|}
\hline Database & Search string \\
\hline EMBASE & $\begin{array}{l}\text { ('paraesophageal hiatal hernia':ab,ti OR 'paraesophageal hernia':ab,ti OR 'paraesophageal hernias':ab,ti OR 'hiatal } \\
\text { hernia':ab,ti) AND (fundoplication:ab,ti OR 'anti reflux':ab,ti OR nissen:ab,ti OR toupet:ab,ti OR dor:ab,ti) AND } \\
\text { (esophagitis:ab,ti OR gerd:ab,ti OR reflux:ab,ti) }\end{array}$ \\
\hline
\end{tabular}

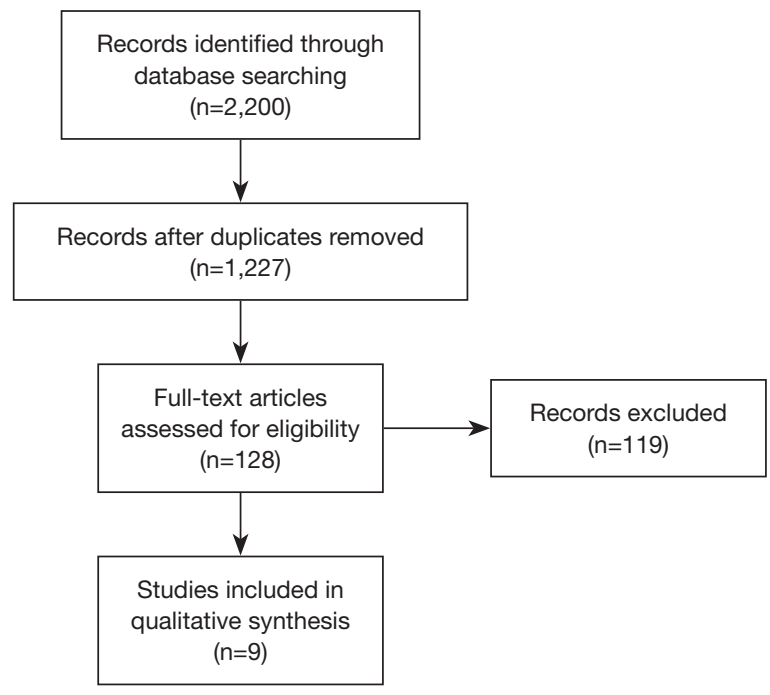

Figure 1 PRISMA flow diagram of included studies.

(Figure 1). Two of the review authors assessed the relevance of the included full-text papers. The articles were assessed independently, and any differences were discussed among the authors to arrive at a consensus within each review pair. One publication was excluded since its study population was included in an earlier included study. Overall, nine papers were included in the review, and their study designs and primary outcomes are outlined in Tables 2,3.

\section{Evidence-based data supporting selective fundoplication}

Different studies favored a tailored approach in performing fundoplication following $\mathrm{PEH}$ repair, selecting patients for an anti-reflux procedure based on the results of preoperative assessment of GERD in terms of symptoms or diagnostic findings.

In an early study from Williamson et al., fundoplication was performed in 19 out of $119 \mathrm{PEH}$ patients in which symptoms and objective evidence of GERD were demonstrated preoperatively (19). In their study, symptomatic improvements were demonstrated in $83 \%$ of cases. Since severe GERD with proven grade 2 esophagitis developed in two NAR patients, the authors supported selective approach to fundoplication during PEH repair. Shortly afterwards, Myers et al. performed a retrospective review of 37 patients diagnosed with PEH (20). Competency of LES as indicated by symptoms of GERD was analyzed selectively with endoscopy or $\mathrm{pH}$ testing. Preoperatively, most patients complained of postprandial pain or pressure $(70 \%)$ and of nausea or emesis (62\%). Only $24 \%$ of patients complained of heartburn. An anti-reflux procedure was performed in 11 patients, and included 9 Nissen fundoplications. Of note, 4/11 patients had their anti-reflux procedure performed without previous GERD symptoms, since the authors were performing this routinely earlier in their experience, while a more selective approach was adopted later. Overall, symptomatic improvement was reported in $92 \%$ of patients. One patient suffered from recurrence, but whether a fundoplication was performed was not specified. Postoperatively, dysphagia without evidence of recurrence was reported in only one patient. The authors concluded that most patients suffering from $\mathrm{PEH}$ will present complaints related to gastric obstruction rather than reflux, and that incompetent LES is not the norm in type II patients. Moreover, the sliding component of type III PEH does not necessarily translate in LES impairment, and a selective approach to fundoplication should be applied to avoid tampering with an intact LES mechanism. Of note, both these earlier cohort studies were conducted on patients who underwent open $\mathrm{PEH}$ repair, which may impact reproducibility of these results in the laparoscopic $\mathrm{PEH}$ repair era.

Two recent retrospective series support a selective 


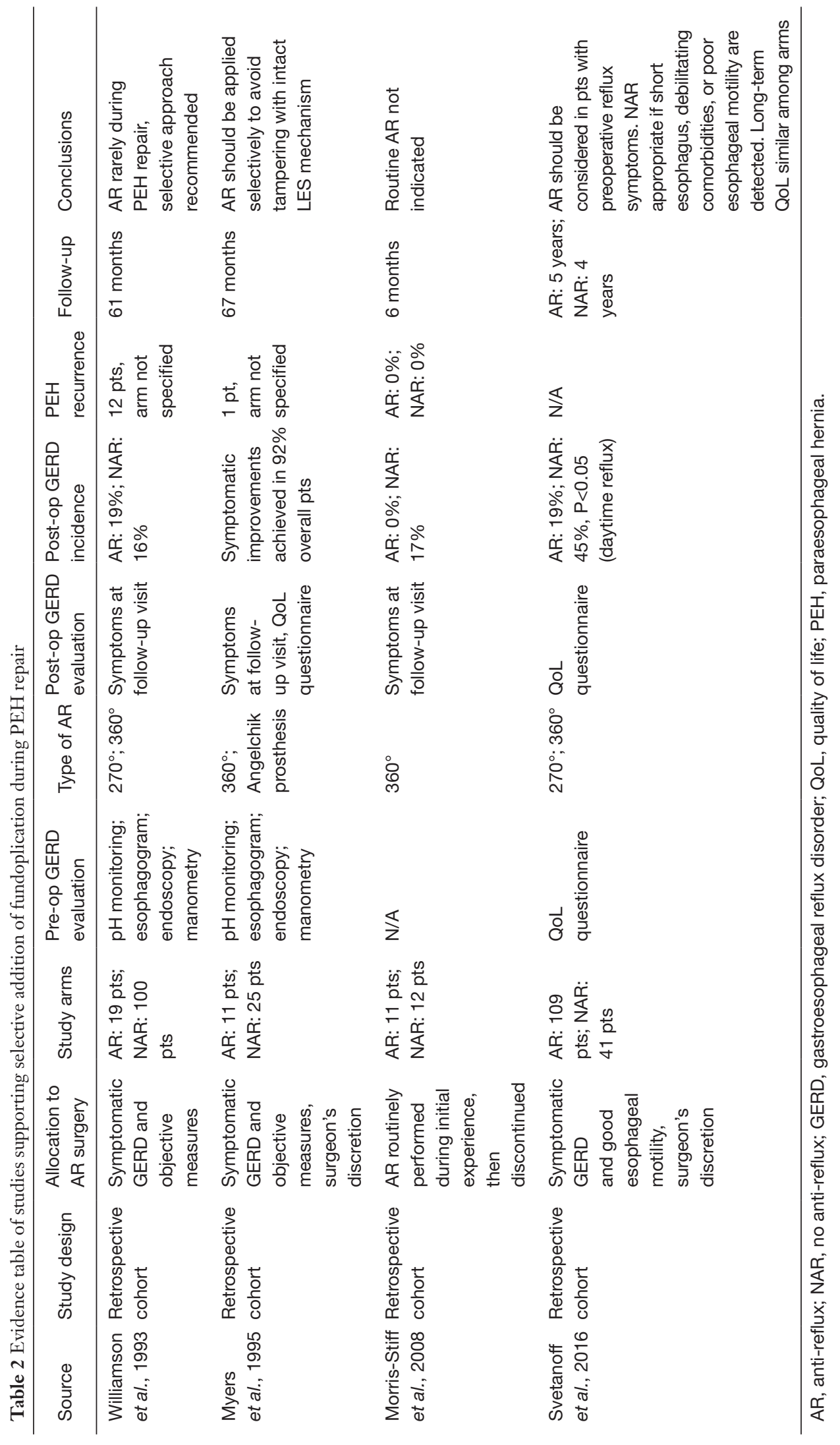




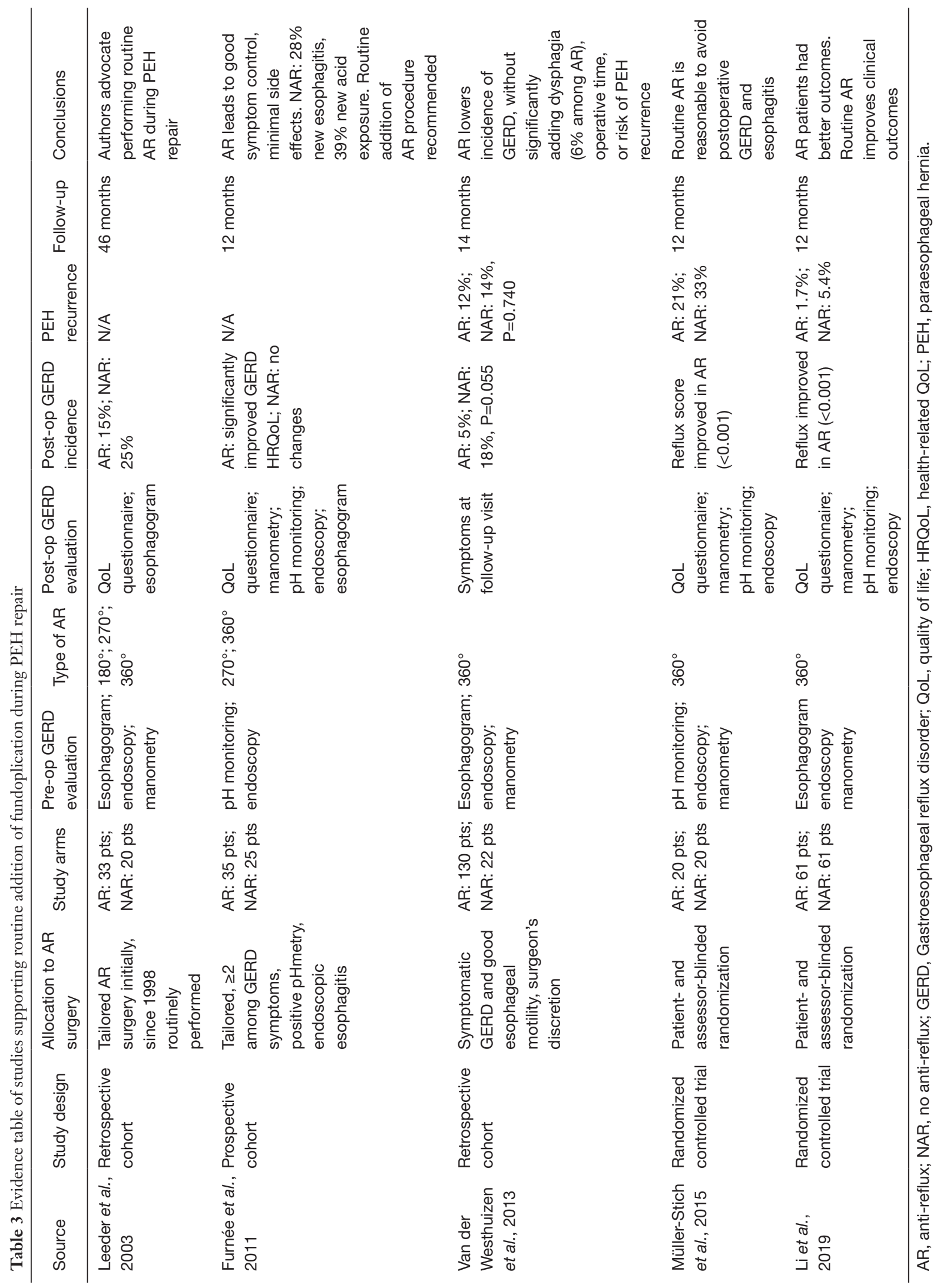


approach to fundoplication following $\mathrm{PEH}$ repair. In the paper from Morris-Stiff et al., the authors discontinued performing routine anti-reflux procedures after experiencing high rates of postoperative dysphagia (21). Overall, 11 patients were included in the earlier AR group, and 12 in the NAR. After a median follow-up of 6 months, two NAR patients developed de-novo reflux esophagitis, while reflux symptoms resolved in all AR patients. No recurrences were seen in either group. However, a concerningly high rate of dysphagia of $82 \%$ was found among AR patients. Due to the relatively low incidence of post-operative esophagitis in the NAR cohort and the high incidence of dysphagia in the AR cohort, the authors concluded that hernial defects can be primarily repaired without the need for fundoplication. Lastly, Svetanoff et al. included 109 patients from the AR group (Nissen or Toupet) and 41 NAR patients (22). Interestingly, there was no overall significant difference in postoperative quality of life (QoL) measures reported by patients from AR or NAR, besides AR patients suffering from more nighttime reflux and postprandial coughing, and NAR patients reporting more daytime regurgitation. Considering these results, the authors recommend selective fundoplication for patients with GERD symptoms. Moreover, since no significant difference in QoL measures was detected, PEH repair alone may be considered in patients with GERD but with poor esophageal motility, a short esophagus, or with debilitating comorbidities. While this series is limited by an important selection bias (the decision to perform a fundoplication was not standardized but rather left to the discretion of the operating surgeon), its strength relies in the long median follow-up of 5 years, which we believe is of foremost importance whenever analyzing outcomes in terms of QoL measures.

\section{Evidence-based data supporting routine fundoplication}

Our search yielded 5 comparative studies favoring routine addition of fundoplication to PEH repair. Among them, 2 are retrospective cohort studies, 1 is a prospective cohort study, and the remaining, more recent 2 were randomized controlled trials.

Among retrospective studies, Leeder et al. sought to address several controversies in PEH repair, including whether to perform an antireflux procedure. In their series, 33 AR patients were included and compared to 20 NAR patients (23). Fundoplication was initially performed on patients with symptomatic GERD, and after a definite timepoint was performed routinely. Based on QoL questionnaires and selectively performed esophagograms, postoperative GERD was seen in $15 \%$ of AR patients and in $25 \%$ of NAR patients. Data on recurrence or dysphagia was not analyzed among the AR or NAR cohorts. Overall, the authors state that their data supported performing routine fundoplication as part of $\mathrm{PEH}$ repair, and included it in their surgical practice. A second retrospective series by van der Westhuizen et al. analyzed 152 patients, of which 130 underwent fundoplication, and 22 did not (24). Generally, need for fundoplication was determined based on subjective and objective findings of GERD. However, $54 \%$ of the NAR patients did not have complaints of heartburn. A mesh was placed in a majority of the included patients (NAR, $86 \%$; AR, 90\%). Even though a significant reduction in GERD symptoms was seen in NAR patients $(18 \%, \mathrm{P}=0.01)$, $45 \%$ were taking PPI postoperatively. Anatomic recurrence rates were similar in both groups $(12 \%$ and $13 \%$, AR and NAR, respectively). Lastly, dysphagia was reported in only $6 \%$ of AR patients. These results supported the addition of fundoplication during $\mathrm{PEH}$ repair to minimize postoperative GERD symptoms, and demonstrated that neither dysphagia nor PEH recurrence were negatively affected by performing a fundoplication.

Furnée et al. conducted the first prospective cohort study on patients diagnosed with large PEH (25). Preoperative assessment of GERD included investigation of classic symptoms, endoscopy, and $\mathrm{pH}$ monitoring for all included patients. Whenever $\geq 2$ out of 3 preoperative evaluations supported diagnosis of GERD the patients were allocated to the AR cohort. A symptomatic and objective evaluation was repeated after 12 months, including an esophagogram to assess recurrence. Overall, preoperative symptoms of GERD were present in $77 \%$ of patients, and the combination of symptomatic and objective evaluation resulted in 35/60 $(58 \%)$ of patients undergoing fundoplication. Symptomatic GERD improvements were reported in $89 \%$ of AR patients, while no significant changes were noted in the NAR cohort. On objective evaluation, normalization of esophageal acid exposure was seen in $61 \%$ of AR patients. Preoperative esophagitis or pathological esophageal acid exposure improved in one third of NAR patients, but either one or both were demonstrated in more than $>50 \%$ of these patients. Moreover, de-novo esophagitis and pathological esophageal acid exposure were seen in $28 \%$ and $39 \%$ of NAR patients, respectively. Recurrent $\mathrm{PEH}$ or wrap migration was seen in $6 \%$ of AR patients 
and recurrent sliding hernia in $12 \%$ NAR patients. Lastly, daily complaints of dysphagia were reported in $9 \%$ of AR patients. It was concluded that NAR patients may be prone to develop de-novo GERD postoperatively, and the authors changed their practice to routine addition of fundoplication during large $\mathrm{PEH}$ repair.

Müller-Stich et al. were the first to perform a randomized controlled trial on the subject (26). In this pilot trial, a patient- and assessor-blinded randomization allocated 40 patients with symptomatic $\mathrm{PEH}$ to either cardiophrenicopexy (NAR) or fundoplication (AR). Of note, type I hiatal hernias were included, and a crural mesh was placed in all cases. Similar to Furnée et al., subjective and objective GERD measures were evaluated preoperatively and at follow-up. At a median follow-up of 12 months, symptomatic GERD scores improved significantly among AR patients but not in NAR patients. At surveillance endoscopy, esophagitis was found in $53 \%$ and $17 \%$ of NAR and AR patients, respectively, and incidence of failed reflux treatment was higher in the NAR cohort. No significant difference was seen in terms of dysphagia. Overall, 33\% and $21 \%$ of NAR and AR patients developed recurrent $\mathrm{PEH}$, respectively. Interestingly, overall QoL measures (beyond GERD assessment alone) did not differ between groups. The authors concluded that adding routine fundoplication is reasonable, without adding significant morbidity or side effects. The largest randomized controlled trial was conducted by Li et al. (27). A total of 122 patients were randomly assigned to AR or NAR. Subjective and objective preoperative assessment and surveillance were reported, and symptomatic type I hiatal hernias were included in the study. In this study, mesh-reinforcement was performed selectively. At 12 months after surgery, GERD-related symptoms were significantly lower in the AR group. Evidence of esophagitis at surveillance endoscopic was reported in $45 \%$ and $14 \%$ of NAR and AR patients. Recurrence was more common among NAR patients ( $2 \%$ vs. $5 \%$ ), and even though this failed to reach statistical significance, it's important to notice that NAR patients had a significantly higher reoperation rate. Differently to what reported by Müller-Stich et al., AR patients were more prone to be fully or partially satisfied with the procedure (88\%) than their NAR counterparts. In summary, outcomes at 12 months seemed to be superior for AR patients as compared to NAR ones, supporting routine fundoplication during $\mathrm{PEH}$ repair.

\section{Discussion}

\section{GERD}

Outcomes of $\mathrm{PEH}$ repair without anti-reflux procedure have been thoroughly investigated with highly variable results reported in different studies. Early experience with hiatal hernia repair showed relatively poor control of GERD symptoms whenever primary repair was attempted without performing any additional fundoplication. A benchmark study by Allison et al. reviewed 421 patients who underwent primary hiatoplasty without fundoplication, with a median follow-up of 22 years, and either recurrent hiatal hernias or GERD following $\mathrm{PEH}$ repair were reported in $33 \%$ of patients (28). The addition of cardiopexy to crural repair has been the subject of previous literature as well. However, once a common procedure, cardiopexy is rarely performed nowadays, mostly due to poor reflux control (29). Indeed, long-term GERD recurrence and the development of de-novo esophagitis have been described at long-term in almost $60 \%$ and $30 \%$ of patients undergoing primary repair and cardiopexy (30). Fundoplication, both anchoring the stomach in an intra-abdominal position and providing sphincter augmentation, lately increased in popularity and became routinely performed during $\mathrm{PEH}$ repair at most centers. Earlier papers from non-comparative studies including patients undergoing routine fundoplication during $\mathrm{PEH}$ repair reported postoperative GERD rates of $8-15 \%$ (31-33). These results are quite similar to the more recent comparative studies included in our review. Overall postoperative GERD rates were found in 16-45\% of NAR patients and in $0-19 \%$ of AR patients (19-27). While four of the included studies recommended selective or no fundoplication, most of these data come from earlier retrospective studies, and the presence of an important selection bias should be considered. Higherquality data from recent prospective series including two randomized controlled trials recommended routine fundoplication, mostly due to a significantly lower incidence of postoperative GERD (24,26,27). Importantly, the abovementioned prospective studies were limited from a short follow-up of 1 year. Whether GERD symptoms may worsen on long-term follow-up is controversial. In the previously mentioned study by Allison et al., symptoms were often reported years since the initial surgery, with or without hernia recurrence (28). However, a recent 
retrospective, longitudinal study from Blake et al. on longterm clinical outcomes reported similar satisfaction scores throughout 11 years of follow-up (34). Unfortunately, only three of our included studies report data with more than 3 years of follow-up.

A selective approach to fundoplication is still adopted at some institutions, even for larger hernias, and surgery is often tailored based on GERD symptoms at presentation (35). However, preoperative $\mathrm{pH}$-metric measurements demonstrated that symptoms are often unreliable indicators of reflux, since increased esophageal acid exposure was found in $69 \%$ of patients who underwent $\mathrm{PEH}$ repair with Nissen fundoplication, while only onethird of patients were symptomatic (36). Swanstrom et al. also demonstrated high rates of abnormal esophageal acid exposure in asymptomatic patients diagnosed with giant PEH (32). One might argue that whenever neither symptoms nor objective findings of GERD are found on preoperative assessment, fundoplication may not be needed. However, the disruption of the crural diaphragm during dissection of the gastroesophageal junction and the resulting risk of developing de-novo esophagitis may represent a strong rationale favoring routine fundoplication (37). Whether one fundoplication may be more suitable than another according to symptoms and objective findings on preoperative assessment has been investigated in a recent review by Andolfi et al. (38). Unfortunately, the authors reported a paucity of highquality evidence in favor of a certain type of fundoplication over another in avoiding reflux and dysphagia following $\mathrm{PEH}$ repair. Reflecting some of the previous considerations, most included studies will ultimately report results of total fundoplication in patients with normal esophageal motility.

\section{Recurrence}

Whether performing fundoplication during $\mathrm{PEH}$ repair might reduce recurrence rates is controversial (39). Data from early experience with laparoscopic PEH repair and fundoplication was contrasting, with some studies reporting no recurrences on esophagogram (40) and others reporting recurrence rates up to $42 \%(41,42)$. Looking at the included studies, data on recurrence rates was available in only 6 papers, and only 4 studies reported recurrence rates for each cohort (19-21,24,26,27). In the series from Morris-Stiff et al., no patients suffered from recurrence (21). However, follow-up for their analysis was only 6 months, which we recognize as a strong limiting factor for this outcome. Data from the included prospective studies is limited by a relatively short follow-up of 12 months as well $(24,26,27)$. All these studies reported higher rates of recurrence in the NAR cohorts (2-21\% vs. 5-33\%, AR vs. NAR respectively) but no significant differences were detected. Longer follow-up data is needed in order to establish a clear role of fundoplication in effectively reducing recurrence rates.

The idea that mesh reinforcement alone may help reduce recurrence rates and eventually represent an ideal adjunct or replacement to fundoplication has also been investigated. The routine use of an absorbable mesh has been supported in a recent commentary from DeMeester (43). However, the use of mesh is still controversial, and recent systematic reviews on the subject showed opposing results. Results from a meta-analysis including three randomized studies with a follow-up of 12 months reported that mesh placement decreased risk of recurrence by a factor of four (44), while a second study including retrospective studies with longer follow-up demonstrated that mesh repair was slightly superior to primary repair in terms of utility scores, and the clinical importance of this finding is unclear (45). Armijo et al. reported on risk predictors for recurrent hiatal hernia following repair with fundoplication in 322 patients from a single institution (46). Recurrence was found in $15 \%$ of patients and was independently associated with large hernia size, while mesh use was not among predictors of recurrence. A selective use of mesh-augmentation in patients with large PEHs is also adopted at our institution.

Lastly, we failed to find data offering a direct comparison between mesh-augmentation versus fundoplication during PEH repair. In a retrospective series of 55 consecutive patients by Linke $e t a l$. who underwent cruroplasty with polypropylene mesh posterior placement, a long-term median follow-up of 72 months was obtained (18). One-third of these patients suffered from GERD symptoms at followup, which seems an inferior result compared to historical controls of fundoplication during PEH repair. However, due to high patient satisfaction in terms of QoL measures and low recurrence rates, the authors concluded that a durable anatomical reconstruction and a certain anti-reflux effects could be achieved through mesh repair alone, with potentially fewer complications than fundoplication (18).

\section{Dysphagia and gas bloating}

Complications from fundoplication are not uncommon, and bloating is a common complaint, reported in up to $58 \%$ of patients following Nissen fundoplication for GERD (47).

Only three of the included studies reported their data on 
dysphagia following fundoplication and hiatal hernia repair $(21,24,25)$. At a median follow-up of 14 and 12 months, van der Westhuizen et al. and Furnée et al. reported postoperative dysphagia in $6 \%$ and $9 \%$ of the included AR patients, respectively. This is a similar rate to what has been reported in previous literature (32). Contrarily, MorrisStiff $e t$ al. reported complaints of dysphagia in $82 \%$ of their patients after 6 months. Such high rates of dysphagia led them to abandon fundoplication in favor of routine primary repair alone. However, criteria for defining dysphagia or longer follow-up were not available. An interesting paper by Anvari et al. (48). addressed the issue of early dysphagia and gas bloating including 433 patients undergoing Nissen fundoplication for GERD. Among them, 73\% suffered from bloating prior to surgery. Postoperatively, 54\% experienced postprandial bloating, and $50 \%$ of patients described these symptoms as either worse or similar to their preoperative status. Among patients with initially worsening symptoms, $68 \%$ were symptom-free at a 2 -year follow-up.

In order to tailor fundoplication during $\mathrm{PEH}$ repair, we believe that an appropriate preoperative assessment should include manometry to exclude possible esophageal motility disorders (49,50). Evidence on the type of fundoplication to perform based on manometric findings is lacking, but low-pressure contractions of the esophagus are likely a contraindication to a Nissen procedure during PEH repair (51).

\section{Conclusions}

The question whether a fundoplication is necessary during $\mathrm{PEH}$ repair is still open. Data on the subject is mostly composed by small retrospective series, and available comparative studies on the subjects have showed mixed results, mostly due to the adoption of different surgical techniques and a significant selection bias. Recent prospective data suggest that routine fundoplication is superior in terms of symptomatic GERD control and avoiding de-novo esophagitis, but further long-term follow-up is needed to confirm these results. Fundoplication did not seem to result in reduced recurrence rates when compared to primary repair alone. Since size of hiatal hernia has been associated with higher recurrence rates, we believe that mesh-augmentation associated with fundoplication represents a reasonable option in repairing larger hiatal hernias.

\section{Acknowledgments}

Funding: None.

\section{Footnote}

Conflicts of Interest: All authors have completed the ICMJE uniform disclosure form (available at http://dx.doi. org/10.21037/atm.2020.03.106). The authors have no conflicts of interest to declare.

Etbical Statement: The authors are accountable for all aspects of the work in ensuring that questions related to the accuracy or integrity of any part of the work are appropriately investigated and resolved.

Open Access Statement: This is an Open Access article distributed in accordance with the Creative Commons Attribution-NonCommercial-NoDerivs 4.0 International License (CC BY-NC-ND 4.0), which permits the noncommercial replication and distribution of the article with the strict proviso that no changes or edits are made and the original work is properly cited (including links to both the formal publication through the relevant DOI and the license). See: https://creativecommons.org/licenses/by-nc-nd/4.0/.

\section{References}

1. Stylopoulos N, Rattner DW. The history of hiatal hernia surgery: From Bowditch to loparoscopy. Ann Surg 2005;241:185-93.

2. Bowditch HI. A Treatise on diaphragmatic hernia. Buffalo Med J Month Rev 1853;9:1-39.

3. Åkerlund ÅI Hernia diaphragmatica hiatus oesophagei vom anatomischen und rontgenologischen gesichtspunkt. Acta radiol 1926;6:3-22.

4. El Khoury R, Ramirez M, Hungness ES, et al. Symptom Relief After Laparoscopic Paraesophageal Hernia Repair Without Mesh. J Gastrointest Surg 2015;19:1938-42.

5. Diaz S, Brunt LM, Klingensmith ME, et al. Laparoscopic paraesophageal hernia repair, a challenging operation: Medium-term outcome of 116 patients. J Gastrointest Surg 2003;7:59-67.

6. Dahlberg PS, Deschamps C, Miller DL, et al. Laparoscopic repair of large paraesophageal hiatal hernia. Ann Thorac Surg 2001;72:1125-9.

7. Wo JM, Branum GD, Hunter JG, et al. Clinical features of type III (mixed) paraesophageal hernia. Am J Gastroenterol 1996;91:914-6.

8. Asti E, Sironi A, Bonitta G, et al. Crura augmentation with Bio-A $\AA$ mesh for laparoscopic repair of hiatal hernia: single-institution experience with 100 consecutive patients. 
Hernia 2017;21:623-8.

9. Maziak DE, Todd TRJ, Pearson FG. Massive hiatus hernia: Evaluation and surgical management. J Thorac Cardiovasc Surg 1998;115:53-60; discussion 61-2.

10. Xie C, Li Y, Zhang N, Xet al. Gastroesophageal flap valve reflected EGJ morphology and correlated to acid reflux. BMC Gastroenterol 2017;17:118.

11. Allison PR. Reflux esophagitis, sliding hiatal hernia, and the anatomy of repair. Surg Gynecol Obstet 1951;92:419-31.

12. Klein WA, Parkman HP, Dempsey DT, et al. Sphincterlike thoracoabdominal high pressure zone after esophagogastrectomy. Gastroenterology 1993;105:1362-9.

13. Fei L, del Genio G, Brusciano L, et al. Crura ultrastructural alterations in patients with hiatal hernia: a pilot study. Surg Endosc 2007;21:907-11.

14. Sloan S, Rademaker AW, Kahrilas PJ. Determinants of gastroesophageal junction incompetence: Hiatal hernia, lower esophageal sphincter, or both? Ann Intern Med 1992;117:977-82.

15. Fein M, Ritter MP, DeMeester TR, et al. Role of the lower esophageal sphincter and hiatal hernia in the pathogenesis of gastroesophageal reflux disease. J Gastrointest Surg 1999;3:405-10.

16. Cuomo R, Sarnelli G, Grasso R, et al. Manometric study of hiatal hernia and its correlation with esophageal peristalsis. Dig Dis Sci 1999;44:1747-53.

17. Emerenziani S, Habib FI, Ribolsi M, et al. Effect of hiatal hernia on proximal oesophageal acid clearance in gastrooesophageal reflux disease patients. Aliment Pharmacol Ther 2006;23:751-7.

18. Linke GR, Gehrig T, Hogg LV, et al. Laparoscopic meshaugmented hiatoplasty without fundoplication as a method to treat large hiatal hernias. Surg Today 2014;44:820-6.

19. Williamson WA, Ellis FH, Streitz JM, et al. Paraesophageal hiatal hernia: is an antireflux procedure necessary? Ann Thorac Surg 1993;56:447-51; discussion 451-2.

20. Myers GA, Harms BA, Starling JR. Management of paraesophageal hernia with a selective approach to antireflux surgery. Am J Surg 1995;170:375-80.

21. Morris-Stiff G, Hassn A. Laparoscopic paraoesophageal hernia repair: Fundoplication is not usually indicated. Hernia 2008;12:299-302.

22. Svetanoff WJ, Pallati P, Nandipati K, Let al. Does the addition of fundoplication to repair the intrathoracic stomach improve quality of life? Surg Endosc 2016;30:4590-7.
23. Leeder PC, Smith G, Dehn TCB. Laparoscopic management of large paraesophageal hiatal hernia. Surg Endosc 2003;17:1372-5.

24. van der Westhuizen L, Dunphy KM, et al. The need for fundoplication at the time of laparoscopic paraesophageal hernia repair. Am Surg 2013;79:572-7.

25. Furnée EJB, Draaisma WA, Gooszen HG, et al. Tailored or routine addition of an antireflux fundoplication in laparoscopic large hiatal hernia repair: A comparative cohort study. World J Surg 2011;35:78-84.

26. Müller-Stich BP, Achtstätter V, Diener MK, et al. Repair of Paraesophageal Hiatal Hernias-Is a Fundoplication Needed? A Randomized Controlled Pilot Trial. J Am Coll Surg 2015;221:602-10.

27. Li ZT, Ji F, Han XW, et al. Role of fundoplication in treatment of patients with symptoms of hiatal hernia. Sci Rep 2019;9:12544.

28. Allison PR. Hiatus hernia: A 20 year retrospective survey. Ann Surg 1973;178:273-6.

29. Janssen IMC, Gouma DJ, Klementschitsch P, et al. Prospective randomized comparison of teres cardiopexy and Nissen fundoplication in the surgical therapy of gastrooesophageal reflux disease. Br J Surg 1993;80:875-8.

30. Styger S, Ackermann C, Schuppisser JP, et al. Reflux disease following gastropexy for para-esophageal hiatal hernia. Schweiz Med Wochenschr 1995;125:1213-5.

31. Champion JK, Rock D. Laparoscopic mesh cruroplasty for large paraesophageal hernias. Surg Endosc 2003;17:551-3.

32. Swanstrom LL, Jobe BA, Kinzie LR, et al. Esophageal motility and outcomes following laparoscopic paraesophageal hernia repair and fundoplication. Am J Surg 1999;177:359-63.

33. Krähenbühl L, Schäfer M, Farhadi J, Reet al. Laparoscopic treatment of large paraesophageal hernia with totally intrathoracic stomach. J Am Coll Surg 1998;187:231-7.

34. Blake AM, Mittal SK. Long-term clinical outcomes after intrathoracic stomach surgery: a decade of longitudinal follow-up. Surg Endosc 2018;32:1954-62.

35. Geha AS, Massad MG, Snow NJ, et al. A 32-year experience in 100 patients with giant paraesophageal hernia: The case for abdominal approach and selective antireflux repair. Surgery 2000;128:623-30.

36. Fuller CB, Hagen JA, DeMeester TR, et al. The role of fundoplication in the treatment of type II paraesophageal hernia. J Thorac Cardiovasc Surg 1996;111:655-61.

37. Casabella F, Sinanan M, Horgan S, et al. Systematic use of gastric fundoplication in laparoscopic repair of paraesophageal hernias. Am J Surg 1996;171:485-9. 
38. Andolfi C, Plana A, Furno S, et al. Paraesophageal Hernia and Reflux Prevention: Is One Fundoplication Better than the Other? World J Surg 2017;41:2573-82.

39. Draaisma WA, Gooszen HG, Tournoij E, et al. Controversies in paraesophageal hernia repair: A review of literature. Surg Endosc 2005;19:1300-8.

40. Athanasakis H, Tzortzinis A, Tsiaoussis J, et al. Laparoscopic Repair of Paraesophageal Hernia. Endoscopy 2001;33:590-4.

41. Hashemi M, Peters JH, DeMeester TR, et al. Laparoscopic repair of large type III hiatal hernia: Objective followup reveals high recurrence rate. J Am Coll Surg 2000;190:553-60.

42. Wu JS, Dunnegan DL, Soper NJ. Clinical and radiologic assessment of laparoscopic paraesophageal hernia repair. Surg Endosc 1999;13:497-502.

43. DeMeester SR. Laparoscopic Paraesophageal Hernia Repair. Surg Laparosc Endosc Percutan Tech 2013;23:429-35.

44. Antoniou SA, Antoniou GA, Koch OO, et al. Lower recurrence rates after mesh-reinforced versus simple hiatal hernia repair: A meta-analysis of randomized trials. Surg Laparosc Endosc Percutan Tech 2012;22:498-502.

45. Obeid NM, Velanovich $\mathrm{V}$. The choice of primary repair or mesh repair for paraesophageal hernia: A decision analysis based on utility scores. Ann Surg 2013;257:655-64.

46. Armijo PR, Pokala B, Misfeldt M, et al. Predictors of Hiatal Hernia Recurrence After Laparoscopic Anti-reflux Surgery with Hiatal Hernia Repair: a Prospective Database Analysis. J Gastrointest Surg 2019;23:696-701.

47. Booth MI, Jones L, Stratford J, et al. Results of laparoscopic Nissen fundoplication at 2-8 years after surgery. Br J Surg 2002;89:476-81.

48. Anvari M, Allen C. Postprandial bloating after laparoscopic Nissen fundoplication. Can J Surg 2001;44:440-4.

49. Jobe BA, Richter JE, Hoppo T, et al. Preoperative diagnostic workup before antireflux surgery: An evidence and experience-based consensus of the esophageal diagnostic advisory panel. J Am Coll Surg 2013;217:586-97.

50. Broeders JA, Roks DJ, Ali UA, Wet al. Laparoscopic anterior 180-degree versus nissen fundoplication for gastroesophageal reflux disease: Systematic review and meta-analysis of randomized clinical trials. Ann Surg 2013;257:850-9.

51. Minjarez RC, Jobe BA. Surgical therapy for gastroesophageal reflux disease. GI Motility Online 2006. doi:10.1038/gimo56.
Cite this article as: Solomon D, Bekhor E, Kashtan H. Paraesophageal hernia: to fundoplicate or not? Ann Transl Med 2021;9(10):902. doi: 10.21037/atm.2020.03.106 